
\title{
25 Research Soure \\ Unnecessary Chest Tube for a Hemodialytic Patient with Multiple Trauma: A Case Report
}

\section{Vahid Reisi-Vanani}

Shahrekord University of Medical Science

Hooman Esfahani ( $\nabla$ esfahani.hooman.md@gmail.com )

Shahrekord University of Medical Science

\section{Case report}

Keywords: Pseudo-pneumothorax, emergency medicine, chest tube, Medical Overuse, Case report

Posted Date: November 22nd, 2021

DOI: https://doi.org/10.21203/rs.3.rs-1004775/v1

License: (c) (i) This work is licensed under a Creative Commons Attribution 4.0 International License. Read Full License 


\section{Abstract \\ Background}

Pneumothorax (PTX) is a life-threatening condition that overdiagnosis could result in increases in mortality and morbidity of patients, this overdiagnosis would be increased if physicians do not manage the patient classically and do not pay attention to the physical exam and history of the patient.

\section{Case presentation:}

A-71-year old man was admitted to the emergency department due to multiple trauma. His vital signs were stable and in examination, there were two lacerations on his scalp with venous bleeding source and galea transaction; there were also some abrasions all over his body including his thorax. In the physical exam, there was no sucking lesion, decreases in respiratory sounds in auscultation or chest deformity but he had little right hemithorax rib tenderness. In more evaluations, there was a suspected visceral line of pleura in his CXR and no plural sliding movement was seen in E-FAST by the operator. Due to the inconsistency in physical exam and radiologic findings we decided to take a chest CT-scan before the insertion of the chest tube that indicated no PTX for him and the suspected visceral line in CXR was skin fold of a permacath for hemodialysis.

\section{Conclusions}

Several conditions could mimic findings of PTX in CXR that every physician should know and pay attention to them besides special attention to the history taking and physical examination to reduce the mortality and morbidity of patients.

\section{Background}

Pneumothorax (PTX) is a life-threatening condition that needs its cure from observation to chest tube insertion and surgery (1). Not only insertion of a chest tube is a painful procedure but also it has complications that occur in about $30 \%$ of cases throw its insertion, application, and removal that some of them could be life-threatening like vascular injuries, infections, etc. these make physicians do this when it is really necessary (2). There are different way to confirm clinical findings of PTX that includes chest Xray (CXR), computed tomography (CT) and lung ultrasonography and although their sensitivity varies widely, their specificity had been reported to be high in the detection of PTX (3). Besides these auxiliary tools history taking and physical examination still are fundamental to medicine, ignoring them could result in mismanagement of patients causing iatrogenic damages and an increase in healthcare costs (4). Here we have presented a case of multiple trauma patients that his clinical finding was not consistent with radiologic findings in the detection of PTX. 


\section{Case Presentation}

A-71-year old man with a history of End-stage renal disease (ESRD), hypertension, and diabetes was brought to the emergency department by EMS service and admitted because of multiple trauma due to falling. In admission, he was agitated and scared in appearance. He had an open airway and could speak without difficulty and while he did not have respiratory distress, he was tachypneic without any crepitation in his chest wall and sucking lesion there or decreases in respiratory sounds in auscultation, but he had little chest wall tenderness. He had stable vital signs with the blood pressure of $130 / 70 \mathrm{~mm}$ $\mathrm{Hg}$, pulse rate of $64 / \mathrm{min}$, respiratory rate of $28 / \mathrm{min}$, and pulse oximetry showed oxygen saturation of $95 \%$ in room air. His pupils were reactive to light and in normal size and Glasgow coma scale of 15/15. In exploring the patient he had two lacerations on his scalp with venous bleeding source that was packed by EMS staff. The larger one was about $15 \mathrm{~cm}$ in length with a galea transection located in the oblique line from his temporal region to frontal region, some abrasions on his upper and lower limbs, and chest wall. He did not have vertebral bodies' tenderness. He had a soft abdomen without any tenderness and stable pelvic and force of all the limbs were $5 / 5$ and the glucometer showed blood sugar of 109 .

In the Focused Assessment with Sonography for Trauma (FAST), there were not any signs of solid organ damage and accumulation of free fluid in Morrison's pouches peri-vesical and pericardial space, but the plural sliding movement was not studied in the initial assessment. Radiologic studies including CXR, brain CT-scan, pelvic x-ray, and laboratory markers had been ordered. When reading his CXR (Fig. 1) we found findings of PTX in his right hemithorax that mandate further evaluations for auscultation and chest wall examination again which had not any more findings than before. Extended FAST (E-FAST) was done and this time the plural sliding movement had not been seen by the operator. In consultation with surgeons in the emergency department about the inconsistency of physical examination findings and radiologic studies we decided to take a chest CT-scan of him while the surgery team was preparing for chest tube insertion, chest CT-scan was done as he was stable in vital signs. Interestingly there were no signs of PTX in the chest CT-scan and there were just some subpleural fibrotic bands in his right hemithorax (Fig. 2). Examine the patient's chest wall for the 3rd time, skin fold of a permacath for hemodialysis in his right hemithorax attracted our attention; He had a history of permacath insertion in his right internal jugular vein 5 years ago and the skin fold in his chest wall was due to this catheter. While we started further evaluation for his falling, he was discharged home against medical advice.

\section{Discussion And Conclusions}

Overdiagnosis of PTX occurs when findings of CXR like distinct radiopaque curvilinear line (Mach band effect) mimics the visceral pleural edge that could be differentiated by paying attention to lung marking signs in the periphery of the line, although this point could not help physicians in situations like unstandardized CXR (5). Some situations like skin fold, patient clothing, past surgeries, pleural cyst, etc. could lead to misdiagnosis of PTX by mimicking an outlined lucent line (6), these conditions besides fatigue and challenges in the emergency department could result in unnecessary procedures and serious effects on mortality and morbidity of patients and health service (7). 
Using lung ultrasonography in the emergency department could also help not to face the same condition or make mistakes as in some studies the LU findings were as accurate as CT-scan in the detection of PTX (8), but this procedure is operator-dependent and could be affected by many factors like use of the inadequate probe, not paying attention to patient's history and physical exam, failure of perception, etc. (9).

Finally, this report showed that although we have several advances in medical facility tools and procedures, still physical examination and history taking is remained fundamental of patient management and should be paying attention more in real practice and educating physicians while relying just on para clinical findings could be misleading and increase the mortality and morbidity of patients.

\section{Abbreviations}

FAST: Focused Assessment with Sonography for Trauma; E-FAST: Extended FAST; CXR: Chest X-ray; CTscan: Computed tomography scan; EMS: Emergency Medical Services

\section{Declarations}

\section{Acknowledgements}

Not applicable

\section{Authors' contributions}

VR: Literature search, data collection, writing the manuscript; HE: Literature search, review of the manuscript and final decision to submit for publication.

\section{Funding}

No funding.

\section{Availability of data and materials}

No datasets were generated or analyzed during the study, but all materials (CXR and CT-scan) are available for review if needed.

\section{Ethics approval and consent to participate}

The treatment protocol was considered to be standard care without any experimental treatment approach or medications.

\section{Consent for publication}

A consent to publish was obtained from the patient himself. 


\section{Author details}

${ }^{1}$ Student Research Committee, Shahrekord University of Medical Sciences, Shahrekord, Iran. ${ }^{2}$ Department of Emergency Medicine, School of Medicine, Shahrekord University of Medical Sciences, Shahrekord, Iran.

\section{References}

1. Rueckel J, Huemmer C, Fieselmann A, Ghesu F-C, Mansoor A, Schachtner B, et al. Pneumothorax detection in chest radiographs: optimizing artificial intelligence system for accuracy and confounding bias reduction using in-image annotations in algorithm training. European Radiology. 2021:1-13.

2. Ball CG, Lord J, Laupland KB, Gmora S, Mulloy RH, Ng AK, et al. Chest tube complications: how well are we training our residents? Can J Surg. 2007;50(6):450-8.

3. Galetin T, Schieren M, Marks B, Defosse J, Stoelben E. Sensitivity of lung ultrasound for the detection of pneumothorax one day after pulmonary resection-a prospective observational study. European Surgery. 2021;53(1):23-8.

4. Padmanabhan Sivakumar S, Sudhakaran S, Surani S, Surani S. Pseudo hydropneumothorax: The importance of history taking in critical care. Critical Care \& Shock. 2014;17(4).

5. Kishimoto K, Watari T, Tokuda Y. Pseudo-pneumothorax: skin fold is an excellent imitator. Case Reports. 2018;2018:bcr-2018-226360.

6. Niazi AK, Minko P, Nahrstedt CJ, Morris AR, Saha PJ, Elliott K, et al. A Case of Pseudo-pneumothorax with Complications. Cureus. 2018;10(9).

7. Moonen P-J, Mercelina L, Boer W, Fret T. Diagnostic error in the Emergency Department: follow up of patients with minor trauma in the outpatient clinic. Scand J Trauma Resusc Emerg Med. 2017;25(1):13-.

8. Zhang M, Liu Z-H, Yang J-X, Gan J-X, Xu S-W, You X-D, et al. Rapid detection of pneumothorax by ultrasonography in patients with multiple trauma. Crit Care. 2006;10(4):R112-R.

9. Pinto A, Pinto F, Faggian A, Rubini G, Caranci F, Macarini L, et al. Sources of error in emergency ultrasonography. Critical ultrasound journal. 2013;5(1):1-5.

\section{Figures}



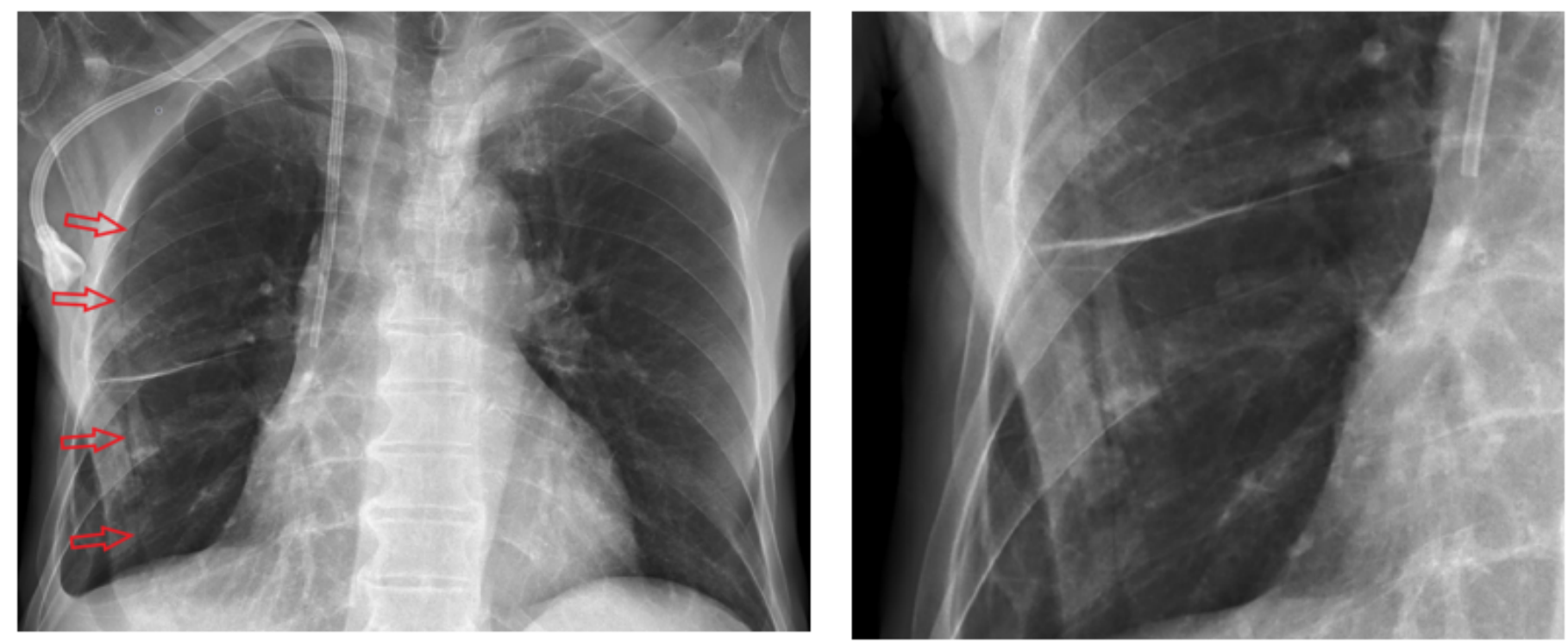

A

B

\section{Figure 1}

A: Chest X-ray of the patient with suspected visceral line of pleura labeled with red marks. B: right hemithorax of the patient with magnification.
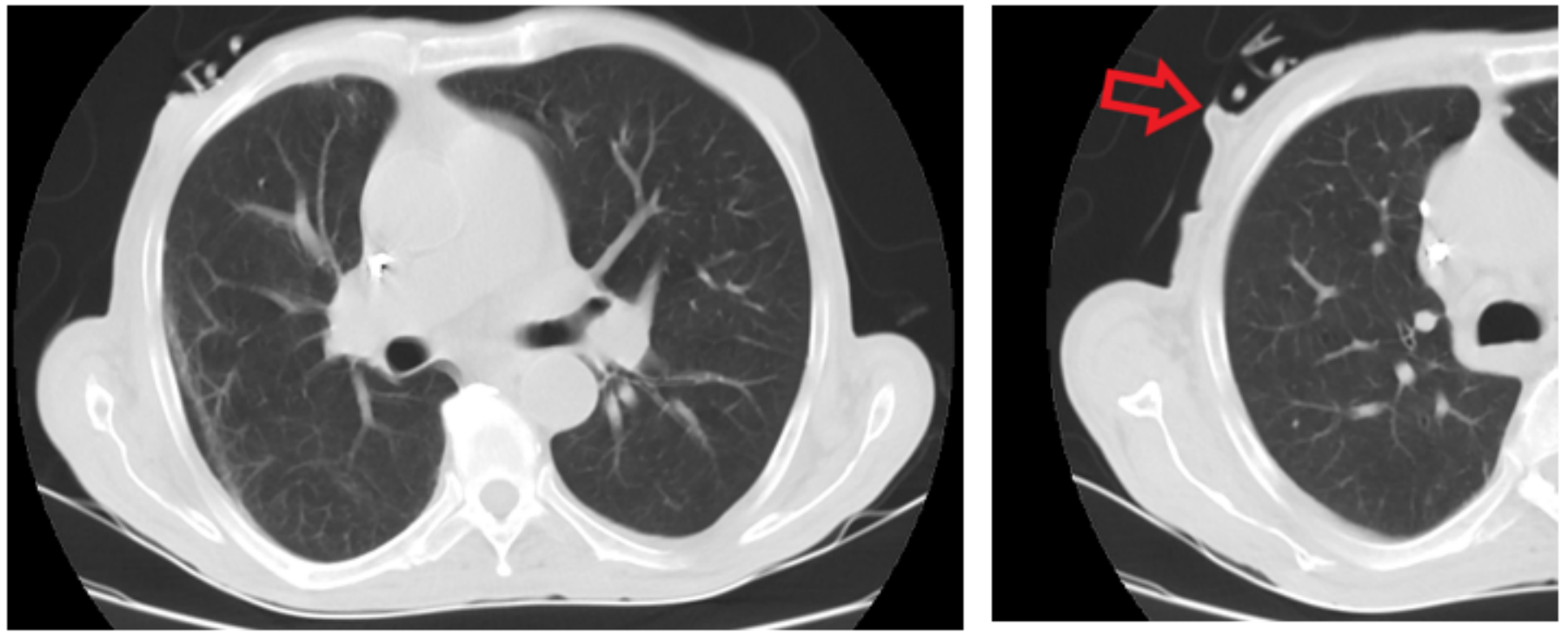

A

B

Figure 2

A: Chest CT-scan. B: right hemithorax with skin fold (red mark). 